\title{
The Use of Lethal Force by Police in the USA: Mortality Metrics of Race and Disintegration
}

(2015-2019)

\author{
John Paull \\ University of Tasmania, Hobart, Australia \\ j.paull@utas.edu.au, john.paull@mail.com
}

\begin{abstract}
Policing in the USA is dangerous for the US public. The objective of the present study is to determine the gross deaths due to lethal force by police and the racial distribution of those deaths compared to the racial distribution of the US population. Longitudinal data reveal that police in the USA kill one thousand people per year ( $\mathrm{n}=1004$ in 2019). Deaths by year and race are presented for the years 2015 through 2019. The racial distribution of victims of US police lethal force is not proportionate to the racial distribution of the US population. Whites account for the largest racial group of deaths, but are underrepresented, accounting for $45 \%$ of police killings (and $60 \%$ of the population). Blacks are over-represented, accounting for $24 \%$ of police killings (and $13 \%$ of the population). Hispanics are proportionately represented, accounting for $17 \%$ of police killings (and $18 \%$ of the population). Others (including Asian, Native American, and others) are under-represented, accounting for $4 \%$ of police killings (and $8 \%$ of the population). The rate of US police killings has been relatively stable for the past five years (with a low of 962 deaths in 2016 and a high of 1,004 deaths in 2019). The US police killing rate in The USA is 3.05 police killings per million of population. The US police killing rate of Blacks is 5.34 per million of Hispanics is 2.63 per million, of Whites is 1.87 per million, and of others is 1.5 per million of population. The US police killing rate of Blacks is 2.86 times the US police killing rate of Whites. US police killing rates compare unfavorably with other jurisdictions. The police fatal shooting rate in Australia is $0.17 \%$ per million of population, one eighteenth of the police killing rate in the USA (an Australian rate of police killings applied to the US population would produce 56 US police killings per year). The reasons for the high rate of police killings in the USA and for the racial disparities of those killings are multifactorial. The valorization of violence and the glamorization of guns are woven tightly into the history and culture of the USA. The metrics of US police killings are a symptom of larger issues within American society. Treating one symptom will not remedy the malady blighting the organism. Is it time for an American societal and rethink of its relationship with violence, in the light of these metrics of disintegration? Is Violent America fixable? Only time will tell.
\end{abstract}

Keywords: Black lives matter (BLM), All lives matter, George Floyd, Justine Ruszczyk Damond, police violence, police brutality, systemic racism.

\section{Introduction}

The present paper examines one manifestation of the US culture of violence, namely the use of lethal force by US police against US citizenry. Violence is woven tightly into the fabric of American history and culture. According to Courtwright (1996) "Violence is the primal problem of American history, the dark reverse of its coin of freedom and abundance". US police, with an armory of one million guns, are tasked with policing US citizenry, with an armory of 393 million guns. There are more guns in the USA than people. The figures are $326,474,000$ people and 393,347,000 guns (Karp, 2018a). The US has $4.3 \%$ of the world's population but $45.9 \%$ of the world's guns held in civilian hands. Most (99.7\%) of the guns in the hands of civilians in the USA are unregistered firearms (Karp, 2018a). The US population holds $57.4 \%$ of the world's cache of unregistered guns in civilian hands (accounting for 392,273,257 unregistered firearms out of a global total of 683,600,887 unregistered firearms in civilian hands) (Karp, 2018a).

By way of contrast, to police their $4.3 \%$ of the global population, the US police account for $4.4 \%$ ( $n=1,016,000$ guns) of the global total of guns held by law enforcement ( $n=23,000,000$ guns) (Karp, 2018b). The gun holdings of US police are globally proportionate to the population they are policing, while the gun holdings of the US population are globally disproportionate. US law enforcement officers face a challenging and sometimes hostile terrain to police. A national survey of US police $(n=919)$, reported that $42.9 \%$ of police respondents agreed with the proposition that: "Always following the rules is not compatible with getting the job done" (Weisburd, Greenspan, Hamilton, Williams, \& Bryant, 2000, p.2). A majority (52.4\%) of the survey respondents agreed that: "it is not unusual for police officers to 'turn a blind eye' to other officer's improper 
conduct" (Weisburd et al., 2000). These authors claim that: "The use of force is a relatively rare occurrence in American policing, but ... when it does occur, it may often escalate to the level of excessive force" (Weisburd et al., 2000).

The escalation to lethal force is the subject of the present paper. The American love affair with violence and brutality is not without social cost. According to one account: "Police in the United States kill far more people than do police in other advanced industrial democracies" (Edwards, Lee, \& Esposito, 2019, p.16.794). Police killings are an index of a dystopic America. To the arsenal of weaponry held by US civilians and US law enforcement, add systemic and racial and economic inequalities, and the situation can become incendiary. Violence begets violence. Is America riding for a fall? There are views that US violence is entrenched (e.g. Kozy, 2013), while others report declines in some indices of US societal violence (Sumner et al., 2015). US police kill one thousand people per year (Tate, Jenkins, \& Rich, 2020). This has spawned the Black Lives Matter movement (BLM, \#BlackLivesMatter) (Black Lives Matter, 2020) and a response of All Lives Matter (\#AllLivesMatter).

The murder of George Floyd (on 25 May, 2020) by US police in Minneapolis and the video capture of it by bystanders (BBC, 2020; Hill et al., 2020) has spotlighted the problem and ignited social unrest and public anger at this category of crime (Sharp, 2020a, 2020b). George Floyd was accused by a teenage grocery shop employee of passing a counterfeit $\$ 20$ bill (not proven at the time of writing) (BBC, 2020). The killing of the Australian woman Justine Ruszczyk Damond (on 15 July, 2017) by US police (also in Minneapolis) after her innocently calling police to report a suspected neighborhood assault on an unknown woman shocked Australians (Australian Associated Press, 2020). Every police killing generates grief and grievance in its wake. The present paper presents metrics of police killings in the USA from 2015 through 2019.

\section{Methods}

Nationwide data on police killings in the USA are not collected by any US Federal Government agency (Edwards et al., 2019). The present paper relies on the database of police killings compiled by the Washington Post newspaper (Tate et al., 2020). The raw data of this dataset was available to the author of the present paper as a comma separated values (CSV) file. The dataset has been compiled, from diverse US media reports, of instances of lethal force by US police. As a consequence of the compilation methodology, the data can fairly be anticipated to be an underestimate of the total instances of lethal force by US police. The extent of the underestimate is not ascertainable. The dataset characterizes victims of lethal force by 'race' as: White, Hispanic, Black, Other, and Unknown. The lethal force data of the present study are extracted from the Washington Post dataset which records US lethal force instances dating from 1 January 2015 through to the present as an ongoing project. The present paper relates the 'race' categories reported in the dataset.

These categories, adopted for the purposes of the present paper, are congruent with the terms for 'race' categories used by the US Census Bureau. For the purposes of the present paper, where used, 'Other' includes Asian, Native American and other. Where the race category of the victim is not reported, it is accounted for here as 'unknown'. Descriptive statistics are extracted from the dataset and reported in the present paper categorized by year (2015-2019) (the five full years of available data) and by race category of the victim (the race category of the perpetrator/s is not recorded in the dataset). Race category data from the United States Census Bureau (USCB, 2020) are used to generate police killing rates per million. For the purposes of comparison, police killings data in Australia are sourced from the Australian Institute of Criminology (Doherty \& Bricknell, 2020) and Australian population data are sourced from the Australian Bureau of Statistics (ABS, 2020).

\section{Results}

The data matrix of police killings in The USA by race and year are extracted from the dataset, and are presented in Table 1. The distribution of race in the population (as per the US Census Bureau) appears in column one of Table 1 . 
Table 1: US killings by Police by Year and Race Category

\begin{tabular}{|r|r|r|r|r|r|r|r|}
\hline Race (\% of population) & 2015 & 2016 & 2017 & 2018 & 2019 & TOTAL $\%$ of killled \\
\hline WHITE (60.4\%) & 497 & 465 & 459 & 451 & 370 & $\mathbf{2 2 4 2}$ & $\mathbf{4 5 . 4 \%}$ \\
\hline HISPANIC (18.3\%) & 172 & 160 & 179 & 165 & 158 & $\mathbf{8 3 4}$ & $\mathbf{1 6 . 9 \%}$ \\
\hline BLACK (13.4\%) & 258 & 234 & 223 & 229 & 235 & $\mathbf{1 1 7 9}$ & $\mathbf{2 3 . 9 \%}$ \\
\hline OTHER (7.9\%) & 38 & 42 & 44 & 40 & 39 & $\mathbf{2 0 3}$ & $\mathbf{4 . 1} \%$ \\
\hline NOT KNOWN (0\%) & 29 & 61 & 81 & 107 & 202 & $\mathbf{4 8 0}$ & $\mathbf{9 . 7 \%}$ \\
\hline TOTAL & $\mathbf{9 9 4}$ & $\mathbf{9 6 2}$ & $\mathbf{9 8 6}$ & $\mathbf{9 9 2}$ & $\mathbf{1 0 0 4}$ & $\mathbf{4 9 3 8}$ & $\mathbf{1 0 0 \%}$ \\
\hline
\end{tabular}

The longitudinal view of total killings per year is presented in Figure 1. The graph shows that the killings total has remained close to constant for the past five years, varying by just 4\%, with a low in $2016(\mathrm{n}=962)$ and a high in 2019 ( $n=1004)$. The distribution of US police killings by race category is presented in Figure 2. White killings are the largest group, followed by Blacks, Hispanics, and Other. There are $9.7 \%$ of killings unidentified by race. The existence of Unknowns means that it is expected that each of the four specified categories are under-reports. It is anticipated that the race of some (or all) of these Unknowns will be resolved and incorporated into the data base as the dataset evolves.

Figure 1: Total US Police Killings Per Year (raw data source: Tate et al., 2020)

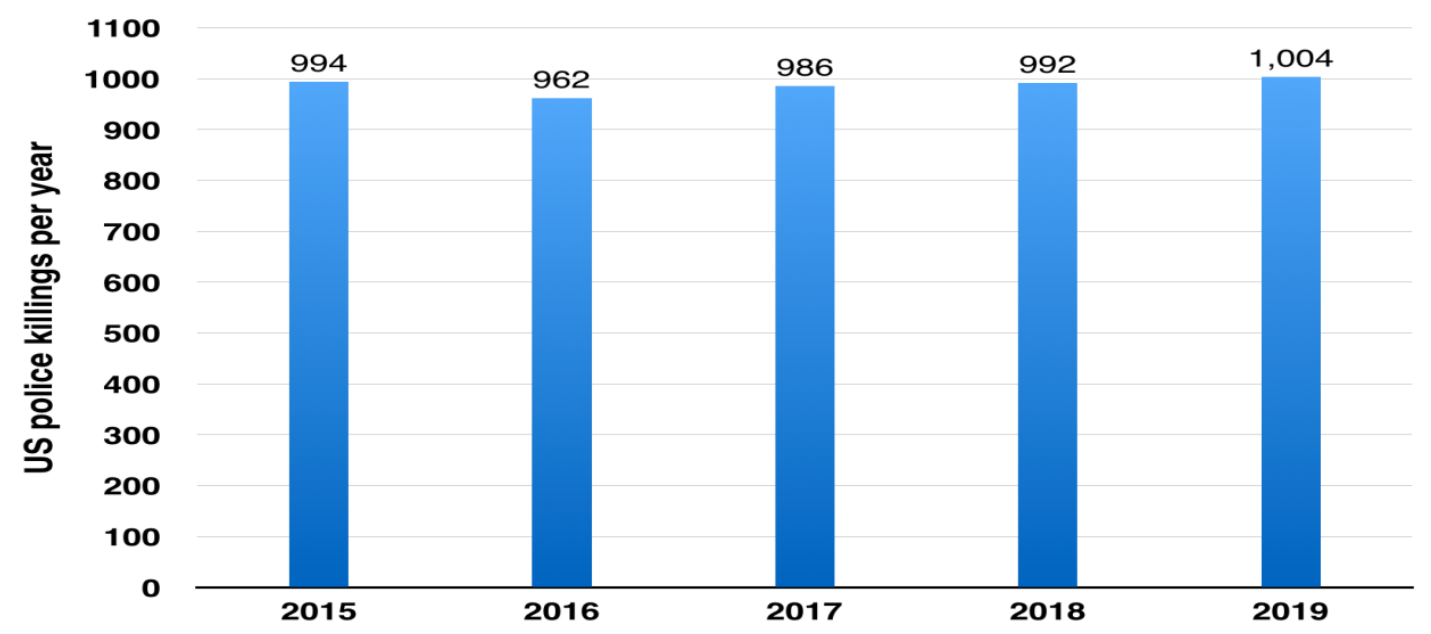

Figure 2: Distribution of Us Police Killings by Race Category of the Deceased (2015 through 2019) (raw data source: Tate et al., 2020)

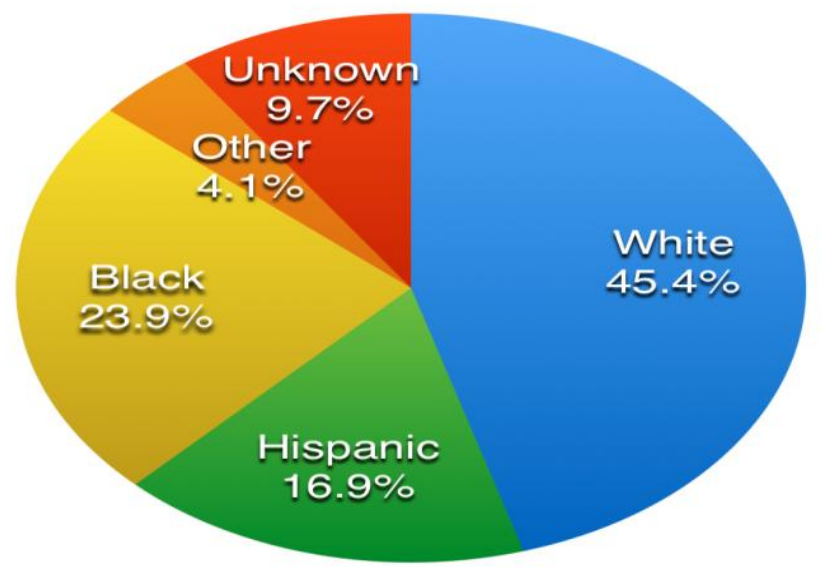


The distribution of the US population by race category is presented in Figure 3. The largest race category is White, followed by Hispanic, Black, and then other. A comparison of the distributions illustrated in Figures 2 and 3 reveals that Whites are under-represented in the police killings (they are $60.4 \%$ of the US population and $45.4 \%$ of police killings). Blacks are over-represented in police killings (they are $13.4 \%$ of the population and $23.9 \%$ of killings). Hispanics are represented close to proportionately to their presence in the population (they are $18.3 \%$ of the population and $16.9 \%$ of police killings). Others are under-represented in the police killings $(7.9 \%$ of the population and $4.1 \%$ of police killings). With the number of deaths by race (Table 1 ) and the distribution of the US population by race category (Figure 3), the killing rate per million per racial category can be calculated (Figure 4). This reveals that Blacks are killed by police at a greater rate than other race categories (at 5.34 per million). Blacks are killed at 2.86 times the rate of Whites, at 2.03 times the rate of Hispanics, and at 3.56 times the rate of others. It has been previously reported that deaths by homicide in The USA are also racially skewed, with Black deaths by homicide reported at 18.7 per 100,000, White deaths by homicide at 2.5 per 100,000, and Hispanic deaths by homicide at 4.5 per 100,000 (Sumner et al., 2015).

\section{Figure 3: Distribution of US Population by Race Category (data source: USCB, 2020)}

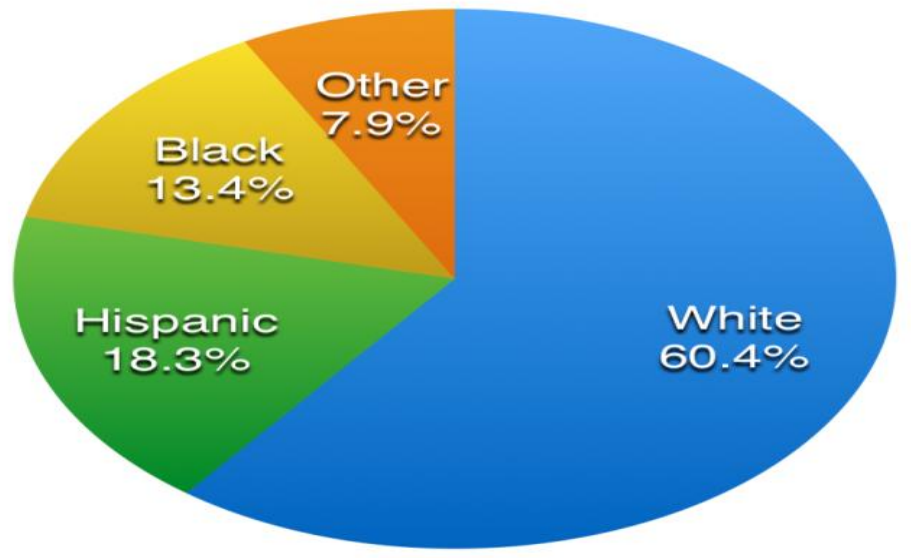

Figure 4: US Police Killing Rates by Race Category for 2019 (raw data source: tate et al., 2020) (Plus the Police Killing Rate in Australia, for Comparison (data source: Doherty \& Bricknell, 2020)

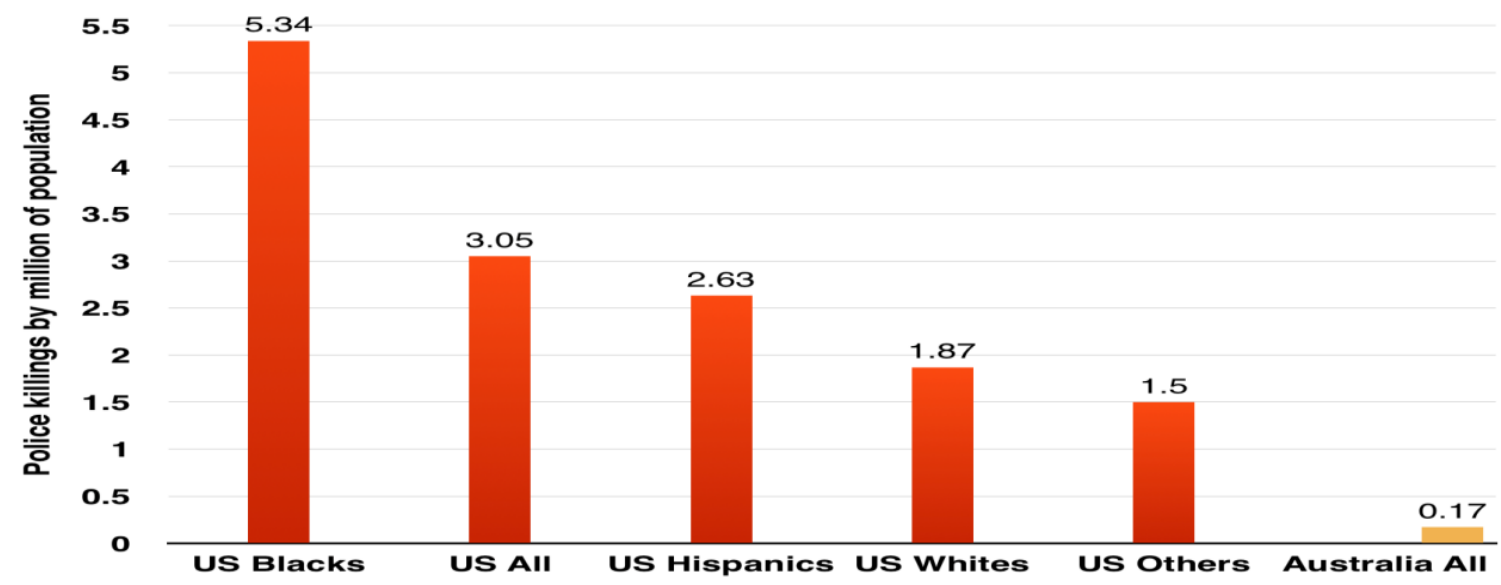

For the purpose of comparison, the Australian rate for police fatal shootings appears in Figure 4. For the period, 2006-07 through 2016-17, there were a total of 47 fatal police shootings in Australia (Doherty \& Bricknell, 2020), averaging 4.3 killings per year. Annual police killings in Australia (in the 11 year period) have ranged from zero (in 1998-99) to 8 (in 1996-97 (Doherty \& Bricknell, 2020). If such a police killing rate were replicated in The USA, there would be 56 police killings per year in The USA. 


\section{Concluding Remarks}

A worthy outcome of the present convulsion of American life over police violence and lethality, as referenced in the present paper and as witnessed in the Black Lives Matter (BLM) movement, would be for the US Federal Government to collect police lethal force data. Better and more comprehensive data can lead to better understanding, and ultimately to better outcomes. Even the mere action of US Federal Government in formally scrutinizing the issue may, of itself, drive down the total episodes of police lethal force (the Hawthorne effect) (Eckmanns, Bessert, Behnke, Gastmeier, \& Ruden, 2006), while at the same time enriching the dataset with further attributes of the victims, the perpetrators, and the circumstances. There are further metrics of US police killings that warrant research. Can the $10 \%$ of police killings where the race is unknown be identified (Figure 2)? What are the broader metrics of US police violence and brutality (remembering that US police killings are but their most extreme manifestation and are likely the tip of an iceberg of police violence)? What are the metrics of prosecutions of police for killings, the rate of successful prosecutions, the penalties applied, the rate of incarcerations, and (since this is the USA) the rate of executions (if any)? What would a matrix of the race of the killer police versus the race of the victim reveal?

Lethal force by US police is a manifestation of the much larger issue of violence within US society. The violence entrenched in US society and culture is a multifactorial phenomenon. The roots of this phenomenon reach deep into the history and cultural experiences and attitudes of the USA. The branches of the phenomena reach into societal attitudes, behaviors, cultural artefacts (e.g., folklore, narratives, movies, and games), homicides, political assassinations, and US foreign policy. Violence has been described as "The American way of life" (Kozy, 2013). Whether the nettle of systemic US police violence, brutality, and racism can be grasped and weeded out of the US garden is a great unknown. The metrics of police killings are but a single symptom of a multitude of troubling features woven tightly into the fabric of US society and culture. Would America be America without police brutality, without the societal valorizing of violence, without the glamorizing of guns? As has been observed: "Violence pervades this culture. Americans not only engage in violence, they are entertained by it" (Kozy, 2013). American culture and history are marinated in violence and permeated with the celebration of violence. Violent narratives of 'How the West was won' and 'cowboys and Indians' are popculture memes.

Accounts of violence pervade US history, including accounts of slavery, lynchings, the McCarthy era, gun-boat diplomacy, 'might is right' interventionist foreign policies, US military colonialism in Korea, Vietnam, and the Middle East, US political colonialism in South America, military culture, and gun apologetics. Violence is embedded in such soft US cultural artefacts as movies, computer games, music and music videos. The militarization of US police and the US prosecution of perpetual warfare are dimensions of the ubiquity of the US culture of violence. The litany of US violence seems endless. How, and even if, it can be reversed is unknown, as is the question: is there the social and/or political will to reverse it? Many cultures, perhaps most cultures, have episodes of violence, but then find ways to move on. Germany plunged the world into two world wars, but now appears to have transcended the unspeakable violence of its recent past and to be now building a non-violent present and future. Is it beyond the whit of The USA to transcend its history and its addiction to and cherishment of violence, and to relegate violence to some pigeonhole of episodic phenomena, rather than to retain it as a systemic ongoing phenomenon?

There is some cause for optimism: "Progress has been made in reducing US rates of interpersonal violence even though a significant burden remains" (Sumner et al., 2015, p.488). Others are less optimistic, for example: "Cultures are extremely difficult to change; changing them requires a sustained effort over several generations. I doubt that Americans are up to the task" (Kozy, 2013). The metrics of US police killings are a symptom of larger issues within American society. Treating one symptom will not remedy the multitude of maladies affecting the organism. Seeking simple solutions for complex problems is also unlikely to yield enduring results. It has been observed: "There is a tide in the affairs of men, which taken at the flood, leads on to fortune; Omitted, all the voyage of their life is bound in shallows and in miseries. On such a full sea are we now afloat; And we must take the current when it serves, or lose our ventures" (Shakespeare, 1623). As the fury against US police use of lethal force (as in the case of George Floyd) and epitomized by the BLM movement gathers momentum, it is time to consider whether America's future is to be (in the words of 
Shakespeare) one of "fortune" or "miseries"? Is the US future to be one of disintegration or of renewal? Is Violent America fixable? Only time will tell.

\section{References}

ABS. (2020). 3101.0 - Australian Demographic Statistics, Sep 2019. 19 March. Canberra: Australian Bureau of Statistics (ABS).

Australian Associated Press. (2020). Family of Australian woman shot dead by Minneapolis policeman hoped city would change after his murder conviction - but George Floyd's death has destroyed that dream. Daily Mail, 30 May.

BBC. (2020). George Floyd: What happened in the final moments of his life. BBC News, 30 May.

Black Lives Matter. (2020). We call for sustainable transformation in our communities: Black Lives Matter $<$ blacklivesmatter.com>.

Courtwright, D. T. (1996). Violence in America. American Heritage, 47(5).

Doherty, L. \& Bricknell, S. (2020). Shooting deaths in police custody. Statistical Bulletin, Australian Institute of Criminology, 19(February), 1-15.

Eckmanns, T., Bessert, J., Behnke, M., Gastmeier, P. \& Ruden, H. (2006). Compliance with antiseptic hand rub use in intensive care units: the Hawthorne effect. Infection Control \& Hospital Epidemiology, 27(9), 931-934.

Edwards, F., Lee, H. \& Esposito, M. (2019). Risk of being killed by police use of force in the United States by age, race-ethnicity, and sex. PNAS, 116(34), 16,793-716,798.

Hill, E., Tiefenthäler, A., Christiaan Triebert, Jordan, D., Willis, H. \& Stein, R. (2020). 8 Minutes and 46 Seconds: How George Floyd Was Killed in Police Custody. New York Times, 31 May.

Karp, A. (2018a). Estimating Global Civilian-held Firearms Numbers, Annexe. Briefing Paper, June. Geneva, CH: Small Arms Survey.

Karp, A. (2018b). Estimating Global Law Enforcement Firearms Numbers, Annexe. Briefing Paper, June. Geneva, CH: Small Arms Survey.

Kozy, J. (2013). Violence: The American Way of Life. Global Research, 12, 1-4.

Shakespeare, W. (1623). The Tragedy of Julius Caesar. In W. J. Craig (Ed.), Shakespeare Complete Works. Oxford: 1978 edition. Oxford University Press.

Sharp, R. (2020a). Chaos at the White House: Secret Service agents in riot gear clash with George Floyd protesters as Donald Trump promises to 'stop mob violence cold' and says: There will be no anarchy! Daily Mail, 31 May.

Sharp, R. (2020b). George Floyd riots spiral out of control: Chaos in 25 cities from New York to LA as protesters torch cop cars, burn down buildings and clash with riot police on a fifth night of violence with hundreds of arrests and injuries. Daily Mail, 31 May.

Sumner, S. A., Mercy, J. A., Dahlberg, L. L., Hillis, S. D., Klevens, J. \& Houry, D. (2015). Violence in the United States: Status, challenges, and opportunities. JAMA, 314(5), 478-488.

Tate, J., Jenkins, J. \& Rich, S. (2020). Every fatal police shooting since 2015: Police shootings database. 29 March. Washington: Washington Post.

USCB. (2020). Quick Facts United States. Suitland, MD: United States Census Bureau (USCB).

Weisburd, D., Greenspan, R., Hamilton, E. E., Williams, H. \& Bryant, K. A. (2000). Police attitudes toward abuse of authority: Findings from a national study. National Institute of Justice Research in Brief, May, 1-5. 